Pasado y Memoria

ISSN: 2386-4745

Núm. 24, 2022, pp. 267-294

https://doi.org/10.14198/PASADO2022.24.11

Estudios

\title{
El hambre que mata. Mortalidad y enfermedad en la Andalucía Oriental rural del primer franquismo (1939-1953)
}

\author{
Hunger that kills. Mortality and disease in rural \\ Eastern Andalusia during the first Francoist \\ (1939-1952)
}

\author{
Gregorio Santiago Díaz \\ Universidad de Granada \\ gregoriosdiaz@ugr.es \\ https://orcid.org/0000-0001-5971-5287
}

Recibido: 22/02/2021

Aceptado: 15/06/2021

Cómo citar este artículo: SANTIAGO DÍAZ, Gregorio (2022). El hambre que mata. Mortalidad y enfermedad en la Andalucía Oriental rural del primer franquismo (1939-1953). Pasado y Memoria. Revista de Historia Contemporánea, (24), pp. 267-294, https:// doi.org/10.14198/PASADO2022.24.11

\section{Resumen}

El primer franquismo (1939-1952) fue un periodo de carestía, miseria, enfermedades y muerte. Considerando el hambre como protagonista, el estudio de la mortalidad de una zona rural de Andalucía Oriental permite relacionar los condicionantes políticos, económicos y sociales con la nutrición. Y también con las condiciones higiénico-sanitarias, las enfermedades y las principales causas de muerte, provocadas tanto directa (enfermedades del aparato digestivo) como indirectamente (enfermedades del aparato respiratorio e infecto-contagiosas) por el hambre.

Palabras clave: Hambre; Enfermedades; Mortalidad; Andalucía Oriental; Primer Franquismo. 


\begin{abstract}
The first Francoist period (1939-1952) was a time of shortage, misery, disease and death. Focusing mainly on hunger as the protagonist, the study of mortality in a rural area in Eastern Andalusia allows for connecting political, economic and social conditioning factors to nutrition. To those added the sanitary conditions, disease and the main causes of death, provoked both directly (digestive system disease) and indirectly (respiratory system and infectious deseases) by hunger.
\end{abstract}

Keywords: Hunger; Disease; Mortality; Eastern Andalusia; First Francoist period.

\title{
Introducción
}

La posguerra en España fue un periodo caracterizado por la escasez, la miseria, el hambre, las enfermedades y la muerte. Desde distintos ámbitos del 'nuevo Estado' franquista, pasando de los espacios políticos hasta los médicosanitarios, se justificaba tal penosa situación debido a las consecuencias de una cruenta Guerra Civil, cuando no señalaban directamente al bando vencido de tamaños males. Los años del desarrollismo franquista, desde la década de los años sesenta, enterraron un pasado negro de necesidad que era mejor olvidar. Es por ello que se hace necesario desenterrar las huellas de los llamados «años del hambre» y aceptar la existencia, en realidad, de una auténtica hambruna determinada por la política económica autárquica y el abastecimiento del régimen, tal y como la historiografía está recientemente haciendo (Del Arco Blanco, 2021).

Erigiendo al hambre como el protagonista de la España del primer franquismo y desde la perspectiva histórica, social, cultural y local, pretendemos, en las siguientes páginas, establecer una relación estrecha entre la mortalidad registrada en la Andalucía rural de secano -Campotéjar ${ }^{1}$ y Dehesas Viejas ${ }^{2}$, de Granada, y Campillo de Arenas ${ }^{3}$, de Jaén- con la situación socioeconómica, nutricional, higiénico-sanitaria y epidemiológica de la población de dicha zona. Ello nos permitirá, por un lado, aclarar y exponer cuáles fueron las causas de muerte y su vinculación, de manera directa o indirecta, con el hambre; y, por otro lado, conocer la tendencia de la mortalidad y establecer, así, una periodización de los años del hambre en la Andalucía Oriental rural.

1. «Tomo 15. Defunciones 1939-1950». Registro Civil de Campotéjar (Granada).

2. «Tomo 8. Defunciones 1934-1940», «Tomo 9. Defunciones 1941-1950» y «Tomo 10. Defunciones 1943-1953»., Registro Civil de Dehesas Viejas (Granada).

3. «Tomo 30. Defunciones 1943-1953». Registro Civil de Campillo de Arenas (Jaén). 
Así, en un primer lugar relacionamos nuestro estudio con la dinámica demográfica y las teorías que nos han ayudado a comprenderla, a saber, la Transición Demográfica, la Epidemiológica y la Nutricional. Continuamos con un breve apunte sobre la política autárquica impuesta por el franquismo, como gran responsable de los años del hambre. En tercer lugar, conectaremos el hambre con los trastornos y enfermedades de la época y la mortalidad, entendiendo las formas de actuación del hambre, así como elaborando una clasificación de las enfermedades que podemos vincular de forma directa o indirecta a este. Por último, a partir de la tendencia de la mortalidad en Andalucía Oriental estableceremos una imagen fija de los años del hambre en la zona, asociándola al contexto socioeconómico y a la realidad de un espacio agrícola de secano.

\section{Dinámica demográfica. Transiciones demográfica, epidemiológica y nutricional}

El estudio de la dinámica demográfica, prestando especial atención a la mortalidad, nos permite entender y contextualizar los avances socioeconómicos que ocurren en las sociedades, a la vez que ofrecen una visión general de las condiciones de vida de la población. Desde los ámbitos demográficos y sanitarios se han propuesto distintos modelos teóricos que buscan presentar una completa explicación para la disminución de mortalidad, la natalidad y la fecundidad, así como analizar sus causas y establecer etapas evolutivas, al menos para los actuales países desarrollados. Aunque estos modelos ponen su acento en diferentes variables, todos son válidos y complementarios a la hora de conseguir una interpretación global de las dinámicas demográficas. La Transición Demográfica (Notestein, 1953), establecía el paso de un régimen demográfico antiguo a uno moderno en tres fases. En una primera, las sociedades agrícolas tradicionales mantenían unas elevadas tasas de mortalidad derivadas de sus condiciones de vida, ya que practicaban una agricultura de subsistencia y tenían poco desarrollados el comercio o los transportes, que daban lugar a un difícil aprovisionamiento de alimentación, vestido o saneamiento (Viciana López, 1998). En aras del equilibrio poblacional, sostenían a su vez altas tasas de natalidad y fecundidad. Esto se habría modificado en una segunda fase en la que las mejoras en las condiciones de vida de la población ante la mayor productividad agrícola y el desarrollo industrial y urbano, había provocado un considerable aumento demográfico, al reducirse la mortalidad y mantener elevadas las tasas de natalidad. El equilibrio solo se recuperaría en una tercera fase, ante el descenso de la fecundidad y la natalidad. 
A principios de los años 70 del siglo XX, Abdel Omran propone la teoría de la Transición Epidemiológica (Omran, 1971), ocupándose de los cambios producidos en la salud de la población en otras etapas. La primera etapa se caracteriza por hambrunas, pestes, epidemias, enfermedades infantiles y puerperales que afectaban a la población joven y que conllevaban altas tasas de mortalidad. En la segunda etapa disminuyen estas crisis epidémicas a la vez que lo hacen las enfermedades infecciosas, aunque seguían siendo las causas más frecuentes de muerte, para acabar con una tercera etapa en la que son las enfermedades degenerativas, las cardiovasculares o el cáncer, las principales causas de muerte.

MacKeown, en 1978, pone de manifiesto la importancia de las mejoras nutricionales de la población que permiten el desarrollo de la Transición Epidemiológica, poniendo las bases de algo actualmente aceptado: la inquebrantable relación existente entre malnutrición y la proliferación de enfermedades infecciosas (Viciana López, 1998: 231). Popkin en 1993 acuñó el término Transición Nutricional, dando otro punto de vista complementario a las dos transiciones anteriores, analizando los cambios producidos en la dieta en tres fases. La primera, desde el Paleolítico hasta el Antiguo Régimen, estaría caracterizada por el hambre. Una segunda en la que las mejoras alimentarias provocan un descenso de la mortalidad y las enfermedades infecciosas, seguida de un periodo en el que tomaron preeminencia las enfermedades degenerativas. Por último, una etapa en la que la población transformó sus hábitos para retrasar la aparición de estas enfermedades degenerativas y aumentar la esperanza de vida (Castelló Botía, 2011:15). No obstante, deberíamos matizar que, aunque existe una relación entre la malnutrición y la mortalidad, no es la nutrición el factor único que influye en la disminución los procesos mortales (Sanz Gimeno; Ramiro Fariñas, 2002:183), sino que la realidad es mucha más compleja e intervienen otras variables que complementan la situación carencial nutricional: higiene pública y privada, hacinamiento en las viviendas, cuidados maternales, atención sanitaria, condiciones climáticas y ambientales, estado de los alimentos, etc.

\section{La España del primer franquismo: autarquía y hambre}

Consumada la victoria del bando sublevado en la Guerra Civil, era hora de institucionalizar el nuevo régimen y configurar así un 'nuevo Estado'- y la propia sociedad- bajo las ideas del ultranacionalismo, el catolicismo y la autarquía económica. Precisamente esta última, que buscaba una teórica autosuficiencia del país, produjo consecuencias fatales para la mayoría de la población española, siendo una de las causas principales por las que se hizo general la escasez 
y la necesidad. El férreo control del comercio y el transporte, la intervención de los precios y la asignación de cupos de entrega llevó a un descenso de la producción agrícola, que determinó la imposición del racionamiento y a la ocultación de productos que se pusieron a la venta, a precios muchas veces desorbitados, en el mercado negro (Del Arco Blanco, 2020a: 37). A finales de los años cuarenta, sus efectos adversos eran notables: inflación, descenso del nivel de vida de los españoles, productos de baja calidad, corrupción o la quiebra de circuitos comerciales tradicionales, entre otros (Cazorla Sánchez, 2000:70-71).

Empero, podemos decir que la autarquía económica se convirtió en uno de los pilares básicos por cuales se articuló el franquismo. Por un lado, hizo posible el control de la población. Las nefastas consecuencias de la Guerra Civil, especialmente durante los primeros años de la posguerra, sumadas a la política económica de intervención del mercado, dieron lugar a una situación de privación, carencias e insuficiencia que abarcó cada una de las parcelas de vida cotidiana de millones de españoles. De esta manera, además de la represión física sobre los vencidos, la propia administración de la escasez por parte del franquismo a partir del racionamiento, hizo que tanto las clases medias como las humildes tuvieran que reorientar sus estrategias y preocupaciones hacia la propia supervivencia diaria, provocando la total desactivación política de estos sectores (Del Arco Blanco, 2010). Por otro lado, la autarquía permitió la configuración de una nueva sociedad, impregnada en la 'cultura de la victoria'(Hernández Burgos, 2016:125), con unos vencedores dispuestos a colaborar y construir la dictadura, en busca de un beneficio por el éxito bélico a partir del cual se sentían legitimados para cometer todo tipo de abusos -sectores sociales afines e incorporados al régimen franquista se enriquecieron gracias al mercado negro (Barciela López, 1985) y al fenómeno del gran estraperlo (Del Arco Blanco, 2018) -y unos vencidos que debían ser castigados, sometidos y controlados, y que no solo sufrieron los rigores de la estrechez de la época por pertenecer a la clases medias y obreras sino también por haber pertenecido al bando republicano.

Por lo tanto, podríamos afirmar que la política económica del primer franquismo se perpetuó en el tiempo, hasta los primeros años de la década de los cincuenta, por cuestiones como la ideología de la construcción del nuevo Estado (Richards, 1999) y por la propia concepción franquista de la sociedad. Sin embargo, el régimen, a través de la propaganda oficial, se escudaba en las consecuencias inherentes a todo conflicto civil (Del Arco Blanco, 2006:242) o en lo concerniente al desarrollo de la Segunda Guerra Mundial (Palanca, 1941:431-432), ya que había propiciado restricciones en el comercio y el transporte (Arias Vallejo, 1941:270), para explicar y justificar la difícil coyuntura 
española. Unas excusas cuestionadas incluso por economistas del franquismo: «(...) la argumentación del gobierno (...) de que la actual disminución del nivel de vida se debe a nuestra guerra civil y a la guerra mundial es falsa y debe ser rechazada $»^{4}$. La cuestión radicaba en la autarquía, como se había advertido a lo largo de la década: Luis Alarcón de Lastra, uno de los primeros ministros de Comercio e Industria, sabía que la intervención económica supondría un obstáculo para la economía española (Payne, 1987:264).

\section{Hambre, mortalidad y enfermedad en Andalucía Oriental (1939-1953)}

Se antoja complicado establecer una cifra de las muertes relacionadas con la hambruna española -entre las 200.000 personas fallecidas por desnutrición y enfermedades que establece Payne y las 600.000 de las que habla Maluqer de Motes-, puesto que serían necesarios más estudios e investigaciones de carácter local y regional que dieran una visión más amplia y concreta a la vez. Y es que estos, hasta ahora, se han ocupado más de esclarecer la situación socioeconómica de la época para la posguerra murciana (Marín Gómez, 2004), conocer el control político y social en Cataluña (Mir Curcó, 2000), constatar la miseria y la escasez desde una visión antropométrica en la región extremeña (Linares Luján; Parejo Moruno, 2013), o estudiar las diferentes y múltiples estrategias de supervivencia que la población tuvo que poner en liza, en los casos de Almería (Rodríguez Barreira, 2008), Málaga (Barranquero Texeira; Prieto Borrego, 2003) y Granada (Román Ruiz, 2015). Así, por lo tanto, quedaría mucho trabajo por hacer, tanto en el tiempo -podíamos ampliar el lapso de tiempo de protagonismo del hambre hasta 1946, e incluso sus consecuencias se dejarán notar durante los primeros años de los cincuenta, al existir una continuidad de la pobreza y la miseria (Del Arco Blanco, 2020b:52-53) -como en el espacio- ya que solo con estudios regionales podremos hacernos una idea de un fenómeno que no fue igual ni heterogéneo en todo el país.

El hambre, por lo tanto, estuvo presente como un fenómeno histórico al que la población española de los años cuarenta tuvo que hacer frente. En este sentido, podemos esbozar sus dos formas claras de actuación mortal. Primero, el estado de subalimentación y desnutrición sentenciaba, de manera inexorable, a la muerte a aquellas personas cuyos organismos, sin esas cantidades mínimas nutricionales, no realizaban correctamente sus funciones vitales. Segundo, la ingesta deficitaria debilitaba a los individuos, minando su estado de salud (Del Cura González; Huertas García-Alejo, 2007:17) y convirtiéndoles en un blanco

4. «Informe de Higinio Paris: la situación económica actual de España.», 1950, 25989, Archivo de la Fundación Francisco Franco. 
fácil para infecciones y enfermedades que, directa o indirectamente, se cobraban sus propias víctimas. Por consiguiente, el hambre no solo es importante porque origina muertes, sino que precisamente es trascendente porque no lo hace. De esta forma, los individuos entraban en un terrible círculo vicioso: eran menos productivos en el trabajo al faltarle las energías para llevar a cabo con éxito sus obligaciones y, a su vez, la deficiente alimentación no le proporcionaba las suficientes fuerzas para realizar dicho trabajo, lo que conllevaba un déficit calórico casi crónico. Esa extenuación determinaba que las infecciones o enfermedades se cebaran con ellos. Ya en 1941 el doctor Arias Vallejo aceptaba que «la alimentación y el trabajo pueden constituir la causa de diversas enfermedades» (Arias Vallejo, 1941: 209). Desesperados, la angustia les indujo a comer todo tipo de alimentos, algunos contaminados o en mal estado, que provocaban enfermedades infecciosas o trastornos nutritivos, mientras que otros escondían unos trágicos efectos secundarios, como la harina de almortas, que originaba el latirismo (Del Cura González, 2004) -una intoxicación que derivaba en una parálisis de las extremidades inferiores-. En 1941 la propia Dirección General de Seguridad advertía de la posibilidad de producirse doscientas mil muertes por hambres y enfermedad (González Duro, 2003: 208).

Sin embargo, no todas estas enfermedades eran mortales, sino que, a pesar de las circunstancias, parte de la población sobrevivió y, desde entonces, han sufrido unas profundas secuelas físicas y psicológicas que vienen determinadas, en primera instancia, por el hambre, puesto que su salud futura y su memoria se han visto condicionadas por este. Cuando nos trasladamos a la Historia Oral, son múltiples y prácticamente unánimes los testimonios que narran y construyen el relato colectivo de los años del hambre. Cristina Abad, de Campotéjar, lo resume de una forma convencional y directa: «he pasado más hambre que un gato con ceguera» ${ }^{5}$. Jesús Martínez, natural de Dehesas Viejas, recuerda cuando apenas era un niño y llegó a su puerta una joven vendiendo higos. Le pidió a su madre que comprara y ella no tenía dinero. Al poco, Jesús vio a su madre llorar, y le preguntó por qué lo hacía: «(...) yo quisiera comprarte higos, pero no tengo dinero. ¿Tú sabes que somos pobres verdad?» (Martínez, 2003:36). Más crudo es el testimonio de Anselmo Marín, de la localidad granadina de Domingo Pérez, puesto que logra hacer un ejercicio crítico de memoria y actualidad: «Lo mismo que yo quiero a mis hijos, mis padres me querían a mí. Exactamente igual. (...). $Y$ sin embargo no pudieron ${ }^{6}$.

5. Cristina Abad Pérez (Campotéjar, Granada, 25/04/1925). Entrevistada el 7 de agosto de 2019.

6. Anselmo Marín García (Domingo Pérez, Granada, 25/07/1935). Entrevistado el 17 de junio de 2020. 
Pero, ¿cuáles fueron las enfermedades o trastornos mortales relacionados con el hambre que estuvieron presentes durante el primer franquismo? Según las causas de muerte, las dividimos en dos grupos: las vinculadas directa o indirectamente con la hambruna española. En primer lugar, las causas de muerte ligadas directamente con el hambre presentan distintas tipologías y agrupamos en dos. De un lado, las enfermedades inflamatorias del tracto gastrointestinal -gastroenteritis, enteritis, colitis, enterocolitis, atrepsia- con síntomas como vómitos, diarrea o dolor abdominal. Y de otro lado, las debilidades congénitas, incluyendo la insuficiencia general de desarrollo, la prematuridad o la debilidad de los nacidos. En segundo término, hallaríamos aquellas causas de muerte indirectamente conectadas con el hambre y que podemos disgregar en dos partes: las que afligen al aparato respiratorio -la bronquitis, la neumonía y la bronconeumonía, inflamaciones de las vías respiratorias- y las infecciosascomo la tuberculosis o la fiebre tifoidea, entre otras.

Atendiendo a esta división y a las ilustraciones 1 y 2 , observamos cuál fue la incidencia del hambre en esta zona de Andalucía Oriental en el periodo 1939-1953. De las 986 muertes registradas en estas localidades, 481 estuvieron vinculadas directa -un 24,44\%-o indirectamente -un $24,34 \%$ - con el hambre, por lo que prácticamente la mitad de las muertes, un $48,78 \%$ de ellas, estuvieron relacionada de algún modo u otro con la situación de escasez, carestía y miseria de la población.

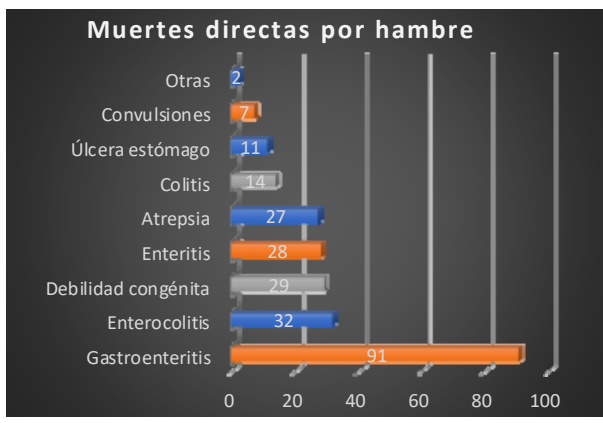

Ilustración 2. Número y causas de muerte relacionadas indirectamente con el hambre en Campotéjar, Dehesas Viejas y Campillo de Arenas, 1939-1953. Fuente: Elaboración propia.

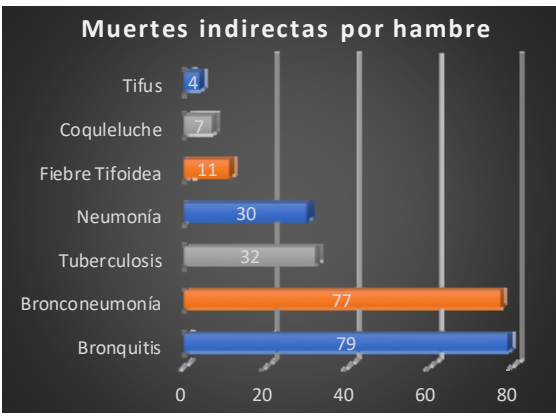

Ilustración 1. Número y causas de muerte relacionadas directamente con el hambre en Campotéjar, Dehesas Viejas y Campillo de Arenas, 1939-1953. Fuente: Elaboración propia.

De los fallecimientos directamente conectados con el hambre, las que mayor peso tienen son las enfermedades del tracto gastrointestinal, así como la atrepsia - desnutrición-. Afectaban de manera clara a la población infantil, puesto que 
su entorno era determinante: la lactancia -fundamental para prevenir enfermedades- el destete- el paso a una alimentación sólida y variada- o la dentición, podían aumentar el riesgo de infección y, por tanto, de muerte (Sanz Gimeno; Ramiro Fariñas, 2002: 167), y estaban muy relacionadas con factores tales como el clima, la estación del año y, sobre todo, la situación socioeconómica (Aguilar Cordero, 2002: 283). La alimentación era de vital importancia, porque determinaba la reacción del organismo ante las enfermedades infecciosas, especialmente en los menores de dos años -un bebé desnutrido tiene 8,4 veces más posibilidades de morir que uno bien nutrido (Dopico; Losada, 2007: 179) -y porque el estado de los alimentos daba lugar a este tipo de trastornos. Ante la escasez, muchas madres suministraron patatas en forma de puré a bebés con apenas meses de vida, y ello les provocaba diarreas y trastornos digestivos como la dispepsia o la propia gastroenteritis (Montero Rodríguez, 1949: 115), provocando pérdidas de peso que, a esta edad, eran peligrosas y mortales (Cussó; Nicolau, 2000: 542-543). Sobre la alimentación se pronunciaban algunos doctores en 1943, pues «1.200.000 niños menores de 2 años (...) hasta ahora, no recibían la ración a ellos adecuada en cantidad y calidad» (Muñoyerro Pretel; Blanco Otero, 1943: 9). Además, en verano aumentaban los casos de gastroenteritis entre la población infantil debido al calor, el difícil abastecimiento de agua o, justamente, el uso como alimento de la patata de la cosecha de mayo. Efectivamente, en esta zona de Andalucía Oriental, de las 165 muertes registradas por enfermedades digestivas, 121 -un 73,33\%-correspondieron a la mortalidad postneonatal, de infantes menores de un año.

Junto con estas, tenemos aquellas causas de muerte que inciden más en la mortalidad neonata -niños fallecidos en los primeros 27 días de vida-, las llamadas debilidades congénitas. Están muy enlazadas con la situación de la madre gestante, tanto por las enfermedades de esta como por, especialmente, la desnutrición durante el embarazo (Pérez Moreda; Reher; Sanz Gimeno, 2015), que no permitía el desarrollo total y completo del feto en la barriga. Unas veces eso daba lugar al aborto, pero cuando el embarazo continuaba, el bebé, débil, moría al poco de nacer (Agra Varela, 1947: 29). Las circunstancias de la madre estaban conectadas con el nivel socioeconómico familiar, ya que se constata que entre los sectores sociales más afectados por el racionamiento y el desabastecimiento existían unas tasas mayores de prematuridad y de recién nacidos de bajo peso (Aguilar Cordero, 2002: 74).

En cuanto a las causas de muerte relacionadas indirectamente con el hambre, las principales son las enfermedades del aparato respiratorio como la bronquitis, la neumonía o la bronconeumonía, asociadas a variables como cuidados infantiles, nivel socioeconómico o estado nutritivo, puesto que 
contra estas solo cabía la posibilidad de usar antibióticos y sulfamidas, llegados a España más allá de los años cuarenta (Sanz Gimeno, 2001: 141). La desnutrición, la salubridad y el hacinamiento de las viviendas ocasionaban un debilitamiento del organismo y aseguraba una fácil transmisión de estas enfermedades. Ciertamente, estas enfermedades son la principal causa de muerte en la Andalucía Oriental entre 1939-1953, puesto que representan un $75,5 \%$ de las causas de muerte indirectas.

El otro conjunto de causas de muerte indirectamente vinculadas al hambre son las infecto-contagiosas, destacando la tuberculosis, la fiebre tifoidea, el coqueluche y el tifus, por orden de letalidad. La tuberculosis -transmitida por vía respiratoria cuando el individuo afectado estornuda, tose o habla (Aguilar Cordero, Rodríguez Moreno, 2002: 440) -se ensañaba con distintos órganos del cuerpo humano, aunque especialmente afectaba a los pulmones. Estaba ligada a la pobreza, la miseria, la mala y escasa alimentación (Molero Mesa, 1994: 200), la insalubridad o el hacinamiento en las viviendas (McAdam; Sharpe, 2010: 367). En esta área de Andalucía Oriental, la tuberculosis estuvo presente prácticamente en todo el periodo de estudio, con al menos un caso por año, aunque los años en los que aumentó fueron entre 1947 y 1948 -9 casos-y entre 1949 y 1952 -9 casos-, de los cuales aproximadamente un 59\% afectó a la población joven -entre 11 y 32 años-. Coincide, de esta manera, con la dinámica española, puesto que en 1948 aumentaron los casos de manera aterradora, con testimonios tan duros como los que hacían referencia a que la «la gente dice que hay que evitar la enfermedad y no curar a los enfermos ${ }^{7}$. Anselmo Marín recuerda que «en una casa de una tía mía entró la tuberculosis y murieron cuatro o cinco» ${ }^{8}$. El primer franquismo intentó luchar contra la tuberculosis a partir del Patronado Nacional Antituberculoso construyendo dispensarios y sanatorios, pero los factores que atenuaron la relevancia de esta enfermedad fue el aumento del nivel nutritivo de la población y su tratamiento con estreptomicina, ya durante los años cincuenta (Pérez Moreda; Reher; Sanz Gimeno, 2015). Por su parte, la fiebre tifoidea, se transmitía por ingerir agua o alimentos contaminados y provocaba anorexia, dolor abdominal, vómitos y diarreas que conducían a unas fiebres altas y a la muerte (Turner, 2010: 802). Estaba asociada, en gran parte, a la insalubridad de muchos pueblos y ciudades en cuanto al abastecimiento público de aguas (Santiago Díaz, 2020: 286). En

7. «Informe R. C. no 305 de la Delegación Nacional de Información e Investigación con el título «Informe sobre la subida de precios que se está produciendo».», 15 de noviembre de 1948, 7715, Archivo de la Fundación Nacional Francisco Franco.

8. Anselmo Marín García (Domingo Pérez, Granada, 25/07/1935). Entrevistado el 17 de junio de 2020. 
Dehesas Viejas, se habla en 1945 de epidemias de fiebres tifoideas «debido a la aglomeración en las casas y la escasez de agua (...) cortadas afortunadamente en poco lapso de tiempo» ${ }^{9}$. Así fue, Campotéjar y Dehesas Viejas tuvieron numerosos casos en proporción a su población de fiebre tifoidea, especialmente en los años de 1941 y 1942 en los que mueren por ella hasta 9 personas. Testimoniales son, por último, tanto el tifus -transmitida por el piojo verde y vinculada a la carestía de la vida, el hacinamiento y la higiene (Rodríguez Ocaña, 2017: 491) -como el coqueluche- un síndrome más leve de tos ferina.

\section{Los 'años del hambre' en la realidad rural de Andalucía Oriental}

La tendencia de la mortalidad en España durante el siglo XX se caracteriza por su continuo descenso, exceptuando los momentos de la gripe española 1918-1920 y la Guerra Civil. Ante tal dato, se ha esgrimido que las consecuencias de los años del hambre para la población española no fueron tan importantes. Aunque lo parezca, no es una contradicción para aquellos que defienden la existencia de una auténtica hambruna en la España franquista. Y es que la población española había iniciado, desde finales del siglo XIX, la fase de transición demográfica, coincidiendo, precisamente, con la modernización económica, urbana, social y cultural del primer tercio del siglo XX, pero tal proceso modernizador se verá contenido por la hecatombe que supone la Guerra Civil (Cubel Montesinos, 1998: 637). Así, la España de posguerra vive un crecimiento poblacional debido al obvio repunte tras el conflicto, tanto en la dinámica demográfica -que continúa su evolución- como por la pérdida de la natalidad, fecundidad y nupcialidad provocada por la guerra. En la provincia de Granada, por ejemplo, hubo en 1936 casi tres mil matrimonios, mientras que en 1940 y 1941 esta cifra superó los cinco mil ${ }^{10}$. A ello habría que sumar que la sociedad de esta zona de Andalucía Oriental es rural, produciéndose los cambios demográficos con mayor lentitud, por lo que mantendrían altas tasas de natalidad y fecundidad -los matrimonios andaluces tenían de media más de cuatro hijos (Cerón Torreblanca, 2005: 27)-a la vez que la mortalidad, por los avances médicos, higiénico-sanitarios y en última instancia, nutritivos, iba descendiendo. En referencia a esto último, durante los años centrales de la centuria fue crucial el progreso de la medicina para disminuir la mortalidad, así como las propias políticas sanitarias del Estado (Sanz Gimeno; Ramiro Fariñas, 2002b: 380) -medios terapéuticos, mejoras en puericultura y obstetricia, la labor de Auxilio Social- puesto que amortiguó la situación (Martínez Carrión,

9. Según el informe del Mapa Nacional de Abastecimientos.

10. Movimiento Natural de la Población, INE. 
2002: 65). España, durante la reorganización sociopolítica y económica de los inicios del franquismo contaba con desigualdades en cuanto a la disponibilidad de recursos sanitarios para la población (Bernabéu-Mestre et al., 2006: 190), siendo más acusada esta nula disponibilidad en el medio rural.

Sin embargo, el argumento de mayor peso puede que sea la tendencia de mortalidad en España son muy generales, puesto que homogeneizan a un país multirregional con diferencias abismales entre regiones y sus condiciones de vida tal y como ha estudiado Rosa Gómez Redondo (1992) y tal y como constatamos en Andalucía, donde la tendencia de la mortalidad es más acusada, siendo más aún, a su vez, en Andalucía Oriental. De hecho, si comparamos la tendencia de la mortalidad por miles de España y de Andalucía entre 1939 y 1953, comprobamos cómo la curva de la mortalidad es más acentuada en Andalucía. Por lo tanto, los datos para el conjunto del país lo que hacen es distorsionar la realidad de las diferentes regiones que lo componen. $Y$ es que podemos hablar de una 'geografía de la hambruna española', puesto que el hambre y sus consecuencias tuvieron más gravedad y efectos en el sur peninsular, particularmente en las zonas agrícolas: Murcia, Castilla y la Mancha, Andalucía y Extremadura (Del Arco Blanco, 2020a: 38). Tomando como referencia las ilustraciones 3 y 4 , comprobamos que la curva de la mortalidad por miles nos muestra tres momentos de máximos. En el gráfico de la tendencia de la mortalidad en España se ven más suavizados que en el de Andalucía, donde son más claros. Y más limpios aún se observan en la tendencia de la mortalidad en los tres municipios objeto de nuestro estudio de Andalucía Oriental, tal y como verificamos en la Ilustración 5, donde podremos observar el porcentaje de muertes relacionadas con el hambre sobre la mortalidad total de la zona en este periodo.

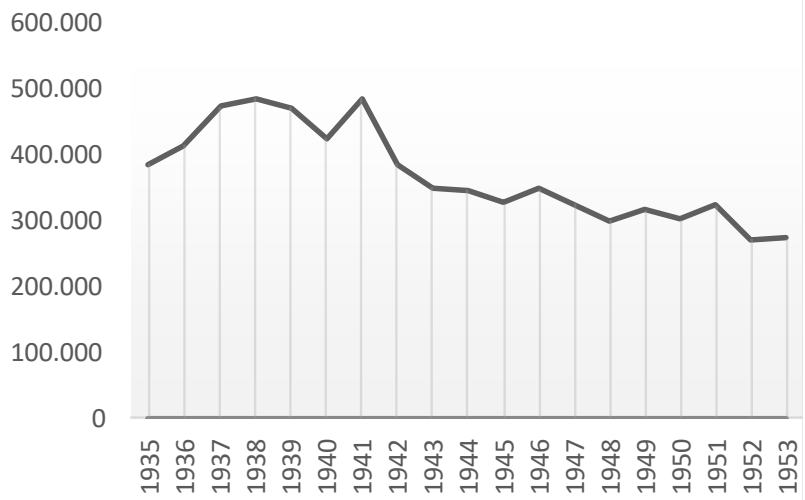

Ilustración 3. Evolución en mile de las defunciones en españa entre 1935 y 1953.

Fuente: Elaboración propia, datos del MNP (INE). 


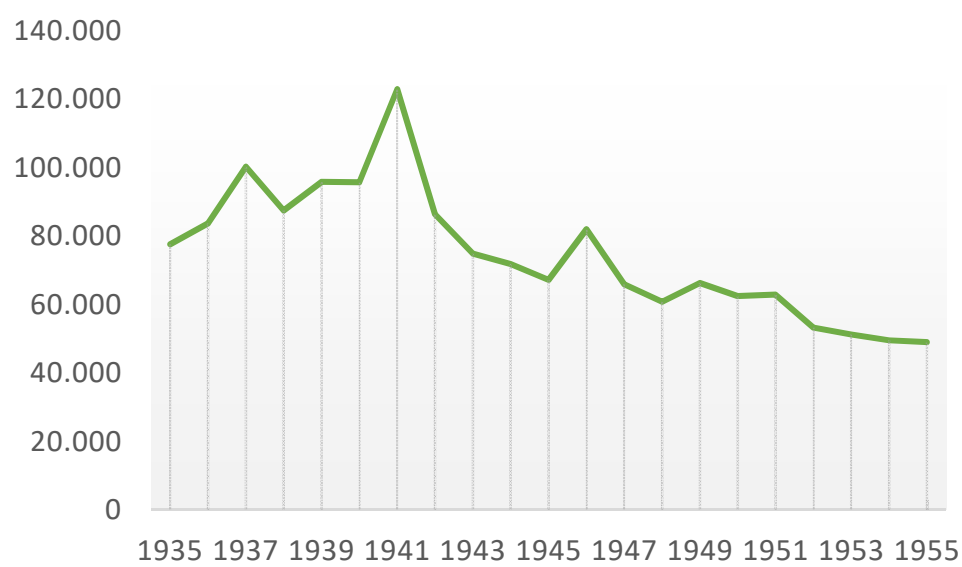

Ilustración 4. Evolución de las defunciones (en miles) en Andalucía entre 1935 y 1955.

Elaboración propia, a partir de los datos del IECA.

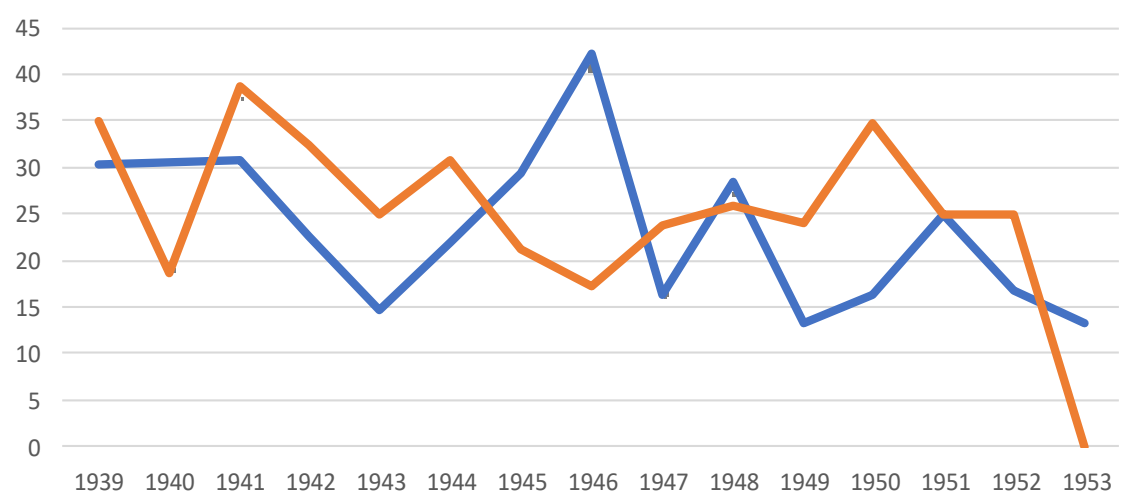

Ilustración 5. Porcentaje de muertes directa (azul) o indirectamente (naranja) relacionadas con el hambre en Andalucía Oriental, 1939 - 1953.

Aproximadamente, durante el periodo que va desde 1939 a 1953, un $23,40 \%$ de media de las muertes estuvieron vinculadas de forma directa con el hambre, y un $25,15 \%$ de manera indirecta. Eso nos arroja una media global de un $48,55 \%$ de las muertes ligadas de forma más o menos estrecha con la situación de necesidad y escasez durante el primer franquismo. Es decir, la mitad de las muertes registradas en este periodo, fueron causadas, de alguna manera u otra, por el hambre.

Así, este gráfico nos muestra una imagen fija de la hambruna española en esta zona rural de Andalucía Oriental. Constatamos, en primer lugar, que existe una conexión inestimable entre las muertes directa e indirectamente 
relacionadas con el hambre. Una es consecuencia de la otra. Podemos afirmar, también, la estrecha colaboración entre las diferentes formas de actuación que tiene el hambre. Las altas tasas de mortalidad ligadas íntimamente al hambre, como vemos en sus picos, nos demuestran que parte de la población fallece, efectivamente, como consecuencia de los trastornos y enfermedades que afectan al aparato digestivo o las debilidades congénitas. No obstante, estas crisis no solo provocan la muerte, sino que existe otra parte de la población que sufre los rigores y las estrecheces de tan violento periodo, pero que sobrevive. Parece obvio que estos individuos supervivientes, tendrán efectos y secuelas, y la más fatal de ellas es que su organismo se ha visto debilitado, por las carencias nutricionales no satisfechas. Esa vulnerabilidad permite la llegada de otras enfermedades, ahora relacionadas indirectamente con la escasez -las del aparato respiratorio y las infecto-contagiosas-, que los lleva a la muerte en los años posteriores a la crisis de mortalidad por hambre, y que dependen de la situación alimentaria e higiénico-sanitaria del individuo y de su entorno. De esta forma, entre 1940 y 1941 el pico de la mortalidad responde a las causas directamente relacionadas con el hambre, para, en el periodo posterior, desde 1942 a 1945, corresponder a las ligadas indirectamente con él. Lo mismo ocurre en los picos de 1945 y 1948, causados por la mortalidad directa, teniendo su respuesta indirecta en 1950 .

$\mathrm{Y}$, en segundo lugar, se advierte de una tendencia de la mortalidad, mucho más acusada que la registrada para la totalidad del país o de la región andaluza, y que nos puede ofrecer una periodización de la hambruna y sus consecuencias en la Andalucía Oriental rural. En este sentido, tendríamos un primer periodo de crítico, desde 1939 a 1941, donde este último sería el año más delicado, puesto que casi un $70 \%$ de la población que muere lo hace por causas relacionadas de alguna forma u otra con la carestía de la vida y enfermedades respiratorias e infecto-contagiosas. Las consecuencias de los tres años de contienda bélica habrían sido decisivas durante esta etapa. Luego, tenemos un segundo periodo crítico entre 1946 y 1948, que sorprende por su magnitud, ya que la mortalidad por causas relacionadas directamente con el hambre supera, con creces -más de un 40\%- a los datos obtenidos para los años de la inmediata posguerra. Esto nos induce a pensar que la hambruna española del primer franquismo, no solo estuvo condicionada por el conflicto civil, sino que incidieron otros factores, ya sean naturales -la pertinaz sequía, malas cosechas- $\mathrm{o}$, sobre todo, políticas -la autarquía impuesta por el régimen franquista, la desarticulación del sector agrario o la ineficaz distribución de alimentos a través del racionamiento. Por último, existen unos repuntes entre 1950 y 1952, muchísimo más suavizados en España y en Andalucía, y que 
se debieron, precisamente, a la mortalidad indirectamente relacionada con el hambre, como la respuesta de estas enfermedades a la debilidad vital de la población superviviente al periodo crítico inmediatamente anterior.

El carácter rural de esta zona de Andalucía Oriental repercute de manera sustanciosa en la mortalidad de la población y nos facilita la explicación de su tendencia durante esta época ${ }^{11}$. Eran localidades dedicadas, en exclusiva, a la agricultura de secano -el $98 \%$ de su superficie de cultivo- desembocando en unos niveles más bajos de bienestar que aquellas zonas que practicaban una agricultura de regadío (Martínez Carrión, 2002: 29-30). Influían en esta actividad, además, cuestiones como las condiciones climáticas -poseían un invierno largo y riguroso ya que este territorio era uno de los «más fríos de la provincia de Granada», según el Mapa Nacional de Abastecimientos- o la pobreza de los suelos, en su mayoría calizos. Para más inri, periódicamente asolaban los campos plagas como la de la palomilla o el hopo. Tales circunstancias no permitían la diversificación de la producción ni un aumento de la productividad. La única solución era utilizar fertilizantes químicos, y en los años cuarenta eran difíciles de conseguir en España. Se hacía realidad el dicho de la época en Dehesas Viejas: «La tierra de este pueblo te dará de comer, pero no te llenará el granero».

Los esfuerzos agrarios se consagraban al cereal y al olivo, cultivos que representaban más del 80\% de las hectáreas en labor. Los motivos estaban claros. Los cereales -trigo, cebada, maíz, yeros, verza o avena-y las leguminosas -lentejas, garbanzos y, en mucha menor medida, habas-, constituían la base principal de la subsistencia y alimentación de la población. El olivar tenía más que ver con el crecimiento del sector antes de la Guerra Civil, que se vio truncado por la política intervencionista del primer franquismo (Barciela López; López Ortiz; Melgarejo Moreno, 1196: 84). No obstante, el aceite seguía siendo un producto vital para una población hambrienta -en efecto, su consumó se expandió geográficamente hablando (Christiansen, 2002: 241)-y muy rentable para sus productores al obtener pingües beneficios por él en el mercado negro (Del Arco Blanco, 2014: 76-77). En la localidad de Iznalloz, vecina de nuestro ámbito estudiado, las familias que mejor sobrellevaron la escasez fueron aquellas que se dedicaron al estraperlo del aceite (Quesada Garrido, 2017: 54).

11. Los datos a partir de los cuales analizamos esta cuestión están en: Comisaría General de Abastecimientos y Transportes, «Mapa Nacional de Abastecimientos, Granada», 1945. 5743, Archivo Histórico Provincial de Granada y en Comisaría General de Abastecimientos y Transportes, «Mapa Nacional de Abastecimientos, Jaén», 1946. 7308, Archivo Histórico Provincial de Jaén. 


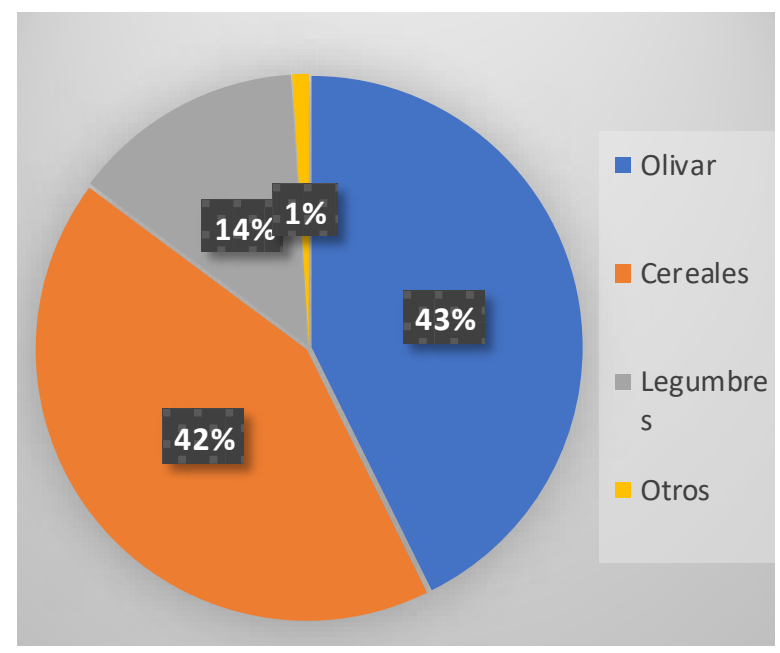

Ilustración 6. Porcentaje de hectáreas dedicadas al cultivo en Campotéjar, Dehesas Viejas y Campillo de Arenas. Fuente: Elaboración propia, datos del Mapa Nacional de Abastecimientos de Granada, 1945.

La agricultura estaba determinada también por el régimen de propiedad de la tierra. En Andalucía Oriental, este se caracterizaba por el multifundio, donde existía un gran número de pequeñas y medianas explotaciones (Del Arco Blanco, 2014: 73), lo que aseguraba un suministro directo desde la tierra, al menos a propietarios, arrendatarios y aparceros, que, todos juntos, representaban a la altura de 1945 el 46,37\% de la población de esta zona rural estudiada. Sin embargo, tanto en Campotéjar como en Dehesas Viejas este sector no llegaría al 25\%, mientras que en Campillo de Arenas alcanzaba el 68\%. El régimen de la propiedad de la localidad jiennense estaba mucho más repartido, especialmente en el cultivo del olivar. Y es que tanto Campotéjar como Dehesas Viejas estaban asistiendo a un proceso con una «marcada tendencia hacia la concentración [de la propiedad] en manos de unos cuantos señores». Así, la mayoría social -algo más de un $60 \%$ - estaría compuesta por campesinos sin tierra que, como los habitantes de las ciudades, dependían única y exclusivamente de su fuerza de trabajo para sobrevivir. En Dehesas Viejas, en efecto, existía «un exceso acentuado de brazos, causa que motiva un casi continuo paro de parte de la población obrera» ${ }^{12}$.

12. Según los informes para cada pueblo del Mapa Nacional de Abastecimientos. 


\begin{tabular}{|c|c|c|c|}
\hline & Trigo & Legumbres & Olivar \\
\hline Campotéjar & $\begin{array}{l}\text { - } 180 \text { propietarios } \\
\text { - } 20 \text { arrendatarios. } \\
\text { - } 5 \text { aparceros. }\end{array}$ & $\begin{array}{l}\text { - } 180 \text { propietarios } \\
\text { - } 20 \text { arrendatarios. } \\
\text { - } 5 \text { aparceros. }\end{array}$ & $\begin{array}{l}\text { - } 50 \text { propietarios } \\
\text { - } 2 \text { arrendatarios. }\end{array}$ \\
\hline Dehesas Viejas & $\begin{array}{l}\text { - } 158 \text { propietarios } \\
\text { - } 20 \text { arrendatarios. } \\
\text { - } 12 \text { aparceros. } \\
\end{array}$ & $\begin{array}{l}\text { - } 158 \text { propietarios } \\
\text { - } 20 \text { arrendatarios. } \\
\text { - } 12 \text { aparceros. } \\
\end{array}$ & $\begin{array}{l}\text { - } 36 \text { propietarios } \\
\text { - } 12 \text { arrendatarios. }\end{array}$ \\
\hline $\begin{array}{l}\text { Campillo de } \\
\text { Arenas }\end{array}$ & $\begin{array}{l}\text { - } 950 \text { propietarios } \\
\text { - } 100 \text { arrendatarios } \\
\text { - } 30 \text { aparceros }\end{array}$ & $\begin{array}{l}\text { - } 950 \text { propietarios. } \\
\text { - } 100 \text { arrendatarios. } \\
\text { - } 30 \text { aparceros. }\end{array}$ & $\begin{array}{l}\text { - } 700 \text { propietarios. } \\
\text { - } 100 \text { arrendatarios. } \\
\text { - } 30 \text { aparceros. }\end{array}$ \\
\hline
\end{tabular}

Tabla 1. Productores agrícolas, 1945. Fuente: Mapa Nacional de Abastecimientos.

\begin{tabular}{|c|c|c|c|}
\hline Municipio & 1940 & 1945 & 1950 \\
\hline Campotéjar & 1.863 & 2.025 & 2.016 \\
\hline Dehesas Viejas & 1.572 & 1.497 & 2.005 \\
\hline Campillo de Arenas & 4.035 & $3.793^{*}$ & 3.849 \\
\hline
\end{tabular}

Tabla 2. Población del ámbito geográfico de estudio. Fuente: INE. *1946

Todo ello, además, en un contexto laboral poco propicio para sus intereses, teniendo en cuenta que el franquismo impulsó una nueva legislación laboral en el campo en la que eran los patronos quienes tenían toda capacidad de decisión, dando lugar a un descenso de los salarios -en 1942 los jornales continuaban siendo los que se habían establecido en 1936 (Ortega López, 2017)-, por lo que los jornaleros se veían relegados a la pobreza y a la subsistencia a la misma vez que tenían que aceptar tales condiciones laborales ante el temor de no volver a ser contratados (Ortega López; Cobo Romero, 2002). No solo eso, sino que, en tales condiciones, los hijos menores de las familias pobres ser vieron obligados a tener que aportar, desde muy pequeños, a la casa, tal y como recuerda Anselmo Marín: «muchos niños trabajando. Quitando hierba en los trigos, en las cebadas, arrancar las lentejas, hierbas, berza, segar, todo eso» trabajando de sol a sol y ganando apenas cinco pesetas. Él mismo empezó a trabajar «cuando tenía ocho u diez añillos, guardando una yegua de un vecino (...)» y en muchas ocasiones el trato a estos niños trabajadores resultaba fatal: «(...) mandándote con la punta del pie, y a los chiquillos que los echaban al cortijo porque no tenían qué comer, maltratarlos $(\ldots) »^{13}$.

13. Anselmo Marín García (Domingo Pérez, Granada, 25/07/1935). Entrevistado el 17 de junio de 2020. 
Pero es que, adicionalmente, los jornaleros estaban expuestos a la coyuntura agraria del momento: las malas cosechas llevaban a una menor producción y, por lo tanto, descendía la cantidad de trabajo necesaria, disminuyendo la cantidad de jornales, lo que a su vez provocaba un empeoramiento de sus condiciones materiales de vida. Solo les quedaba la puesta en práctica de diversas estrategias de resistencia y subsistencia cotidiana (Hernández Burgos; Leira Castañeira, 2020: 85) que iban encaminadas a aliviar, en parte, la miseria y carestía del momento: compraban productos que no pagaban hasta que cobraban los jornales de la cosecha, dando lugar a un círculo de condiciones precarias que se repetía (Quesada Garrido, 2006: 270), o buscaban en el monte aulagas que luego se vendían por un poco de dinero en la yesera o en la panadería donde estos arbustos eran usados en los hornos (Santiago Díaz, 2017: 182). Remarcable fue, también, la existencia de lazos de solidaridad en este tipo de comunidades, a pesar de la existencia inevitable de delitos famélicos contra la propiedad. Cristina Abad recuerda cuando: «una vez tocó un pobre a la puerta, de esos pidiendo, la criatura 'esmayao', y mi papa [le dijo] asómese y verá usted lo que tengo. [Era] una sartén de migas y todos alrededor de la sartén a comer. Mire usted lo que tengo, ¿quiere usted comer? Dice, pues sí. Y con mi hermano acostado estuvo el hombre comiendo migas con nosotras». Anselmo no olvidará nunca a la dueña del horno de un molino cercano a su pueblo: "Tenía una espuerta, pero una espuerta, y la hacía pedazos y todo el que iba allí le daba un pedazo de pan. Todo el que iba allí... pero un pedazo de pan bueno. Todos los días la tenía llena de pan. Esos se portaron muy bien, pero otros no» ${ }^{14}$.

También fue habitual la movilidad de hijos de familias humildes por los cortijos o casas de gente pudiente, practicando la mendicidad, tal y como cuenta Luisa Hernández-Carrillo, de Campotéjar: «estaban todo el día en mi puerta, doña María [su madre] deme usted un cachico pan (...) deme usted una poquita pringue. Eso era una lástima. De mi casa no se iba nadie sin una limosna» ${ }^{15}$. No obstante, había quiénes tenían que recurrir a pequeños hurtos para subsistir. En Dehesas Viejas desapareció un pequeño cabritillo y averiguaron había sido una mujer «que era de las más indigentes del pueblo». Fue llamada al juzgado y declaró ser culpable y que lo había hecho sin ayuda. «Como el cabritillo era ya irrecuperable, no hubo sanción y todo quedó en antecedentes» (Martínez, 2003: 27).

14. Cristina Abad Pérez (Campotéjar, Granada, 25/04/1925). Entrevistada el 7 de agosto de 2019.

15. Luisa Hernández-Carrillo (Campotéjar, Granada, 12/12/1930). Entrevistada el 12 de julio de 2016 
El sector industrial, transformador de los productos agrícolas, estaba formado por fábricas de pan y molinos de aceite, aunque Campillo de Arenas tenía una mayor variedad en este sentido, precisamente por obtener una mayor cantidad de habitantes. Quienes tenían la fortuna de trabajar en este sector, pudieron sortear los rigores de la época de alguna manera. Cristina Abad confiesa que no pasaron más hambre en su casa "porque mi padre estaba en el molino (...) y por lo menos harina se traía y hacíamos migas ${ }^{16}$. El padre de Jesús Martínez era el cartero del pueblo y "con sus ligeros conocimientos en carpintería hacía cuatro chapuzas que ayudaban un poco a la economía familiar, pero no daba para caprichos» (Martínez, 2003: 35). A su vez, el sector terciario se encontraba en dinamismo debido a la existencia de tabernas y posadas, que formaban parte del tiempo de ocio de la población y que bien pudieran deberse a la posición de estas localidades, a medio camino entre las ciudades de Granada y Jaén.

Con este panorama socioeconómico, la Andalucía Oriental rural fue muy vulnerable a las épocas de malas cosechas. Durante los primeros años de posguerra la desarticulación vino marcada por la nueva política agraria del franquismo y, en 1945, por la sequía continuada en Granada ${ }^{17}$, las dificultades de España para abastecerse en el mercado exterior y por la propia política de intervención económica, que estableció cupos forzosos para los agricultores que generaron más escasez aún, puesto que estos ocultaban parte del grano cosechado y lo vendían en el mercado negro para obtener beneficios: «(...) los que eran labradores, que tenían mucho trigo, no lo llevaban al almacén y lo vendían a 600 pesetas la fanega (...)» tal y como recuerda nuestra entrevistada Luisa Hernández-Carrillo ${ }^{18}$.

La política de abastecimientos, ineficaz y desigual, influyó también de manera notable. Mientras que en las ciudades el reparto del racionamiento era mayor y mejor, en las zonas rurales era de menor cantidad y de peor calidad. Se daba por hecho que las localidades calificadas como 'agrícolas' podían acceder directamente a los alimentos que producía la tierra. A la altura de 1946, en España los racionamientos eran «tan escasos que no bastan para mal vivir diez días de cada mes en las capitales y cinco en los pueblos ${ }^{19}$ ». Por lo tanto, el racio-

16. Cristina Abad Pérez (Campotéjar, Granada, 25/04/1925). Entrevistada el 7 de agosto de 2019.

17. «Informe de las Cámaras de Comercio sobre la situación económica de España en el tercer trimestre de 1945.», marzo de 1946, 1385, Archivo de la Fundación Francisco Franco.

18. Luisa Hernández-Carrillo (Campotéjar, Granada, 12/12/1930). Entrevistada el 12 de julio de 2016.

19. «Problemas de abastos por mala cosecha de año anterior.», 1946, 10898, Archivo de la Fundación Nacional Francisco Franco. 
namiento era insuficiente, tanto es así, que algunos estudios constatan que el racionamiento de 1941 ofrecía un déficit del 66\% de calorías con respecto a la dieta necesaria para satisfacer las necesidades más elementales (Rodríguez Barreira, 2013: 157).

Eran los municipios los que distribuían los artículos racionados, después de recibir el encargo de la delegación provincial de la Comisaría de Abastecimientos, pero el reparto llegó a tener importantes obstáculos que no solo venían marcados por los problemas de transporte sino por la corrupción. En este sentido, la Delegación Provincial de Granada dejó claro al ayuntamiento de la localidad granadina de Benalúa de las Villas que informara en los primeros días de cada mes del «abastecimiento de todos los artículos sometidos a racionamiento en esa localidad, haciendo constar los días que están abastecidos $y$ cantidad suministrada por ración ${ }^{20}$. Sin embargo, el acalde hizo caso omiso a estas obligaciones llegando a ser multado en reiteradas ocasiones por no haber remitido el conduce -documento que formalizaba la entrega de los productosde importantes cantidades de kilos de harina ${ }^{21}$.

Uno de los peores años para el abastecimiento en la España del primer franquismo fue, efectivamente, 1946, por lo que esta zona de Andalucía Oriental sufrió los envites de las malas cosechas de 1945 y la consecuente desorganización del racionamiento. A finales de ese año se podía constatar la difícil disponibilidad de alimentos, según un Informe de las Cámaras de Comercio, en el que los productos «apenas bastaban para la alimentación familiar»" en la región oriental andaluza. El racionamiento de aceite, por ejemplo, era escaso, a pesar de ser una zona predominantemente olivarera, y había que obtenerlo en el mercado negro (Del Arco Blanco, 2014: 79). Cristina Abad recuerda que en el racionamiento de Campotéjar te daban «nada más que una miaja de pan. Solo pan, pan y poco. Sí, pan de cebada. No estaba duro, pero tenía cada raspa $a s i{ }^{23}$. Todo esto se ve reflejado en una nueva tendencia al alza de la mortalidad, como así lo atestiguan los repuntes de la mortalidad en Andalucía Oriental en 1948 y 1951.

Sin embargo, junto con estos factores socioeconómicos, existían otras variables que potenciaban la mortalidad relacionada con el hambre. De una

20. «Informes sobre el abastecimiento de los pueblos», 17 de abril de 1944, Caja 72, Pieza 6, Archivo Municipal de Benalúa de las Villas.

21. «Inspección de abastecimientos», 5 de mayo de 1945, Caja 73, Pieza 4, Archivo Municipal de Benalúa de las Villas.

22. «Informe de las Cámaras de Comercio sobre la situación económica de España en el tercer trimestre de 1945.»

23. Cristina Abad Pérez (Campotéjar, Granada, 25/04/1925). Entrevistada el 7 de agosto de 2019. 
parte, las condiciones de higiene tanto pública como privada. Los saneamientos y el estado de urbanización de las calles de estos pueblos estaban en pésimas condiciones. En el municipio cercano de Montejícar se denunciaba la dificultad para transitar por la acumulación de basuras en ellas ${ }^{24}$. En Dehesas Viejas, de hecho, se utilizó mano de obra del paro obrero para solucionar el problema de sistema de alcantarillado, inexistente. No obstante, una de las peores partes era el hacinamiento en las viviendas, especialmente para las familias jornaleras, que tenían muy a menudo que compartir viviendas pequeñas, incluso con animales domésticos. Según los datos de Dehesas Viejas, existían un total de 218 viviendas para una población que, sin contar con los cortijos adyacentes, ascendía a un total de 1435, dando un coeficiente de más de 6,5 personas por vivienda. Cristina Abad, que era la quinta de once hijos, habla de que su casa constaba de dos habitaciones, y que en una de ellas dormía con sus padres y sus hermanas. En el hogar de Anselmo Marín convivían hasta once personas en una pequeña casa de dos o tres habitaciones, durmiendo unos «en la cocina, [otros en] un colchón en el suelo, otros de otra forma...» ${ }^{25}$.

A todo ello se unía la poca disponibilidad de recursos sanitarios en la zona. Estas localidades tenían un Inspector Municipal de Sanidad, el médico del pueblo, padre de nuestra entrevistada Luisa Hernández-Carrillo y que no daba abasto: «Mi padre atendía a todo el mundo. A todo el mundo. Y abusaban de él. Porque ponía la consulta por la mañana y a lo mejor se acordaban de ir por la tarde, 'pero mujer, ¿por qué no has venido por la mañana?'. El pobre estaba todo el día... ${ }^{26}$. Y es que las zonas de carácter rural obtuvieron unos desiguales y tardíos servicios sanitarios, lo que hizo que la mejora en las condiciones de la calidad de la vida sufriese retrasos, permaneciendo una mortalidad más elevadas que, por ejemplo, las ciudades, donde los recursos en sanidad eran más y mejores distribuidos (Beteta Avio, 2018: 9).

De otra parte, los que tienen que ver con las necesidades básicas de la población como son el acceso al agua, al alimento y al vestido. El abastecimiento de agua potable habría sido difícil, complejo y deficitario para la población de esta zona de la Andalucía Oriental, dependiendo de fuentes o pilares. En Campotéjar existía uno y en Dehesas Viejas dos, totalmente insuficientes para abastecer a más de tres mil personas que acudían a ellas a diario -una tarea

24. Según la Sesión del 15 de noviembre de 1941, Libro de Actas del Ayuntamiento de Montejícar, 1940-1942.

25. Anselmo Marín García (Domingo Pérez, Granada, 25/07/1935). Entrevistado el 17 de junio de 2020.

26. Luisa Hernández-Carrillo (Campotéjar, Granada, 12/12/1930). Entrevistada el 12 de julio de 2016. 
de mujeres y niños, como confirma Anselmo Marín: «A mí mi madre muchas veces me ha mandado, anda y te traes un cántaro de agua» ${ }^{27}$. En Campotéjar, por ejemplo, se usaron dos ríos con caudal como recurso hídrico. Siguiendo con las necesidades vitales, una de las más importantes, la del alimento, era insuficiente y monótona. La dieta era poco variada y generalmente estaba formaba por platos muy parecidos y hechos a base de productos que se cultivaban en la zona. Las migas, hechas con pan, aceite y grasa animal o distintos potajes de legumbres, a saber, garbanzos, lentejas o judías con algo de tocino y patatas. Cristina Abad rememora que el potaje se hacía con manteca «porque tocino no había» y que el café que bebían era de remolacha. Anselmo afirmaba que su madre: «(...) Hacía sus guisados de patatas, las poquillas que había, de cardillos, (...) una tortilla de collejas, todo eso...» y que con un cuarterón de aceite «que es como un dedal [se] hacía en mi casa mil comidas» ${ }^{28}$. Por último, en cuanto al vestido, la población más humilde utilizaba tejidos de lana o algodón y, para el calzado, albarcas de goma o alpargatas de cáñamo y esparto, mientras que los sectores sociales más acomodados podían llevar zapatos de cuero. No obstante, la población tenía pocas prendas de vestir, que iban pasando de hermanos grandes a pequeños -aunque según Anselmo Marín a veces no había ropa ni para pasarse de hermano a hermano- o se remendaban para poder seguir usándolos. El mismo Anselmo recuerda que «yo me he puesto calzones con más remiendos que...puf». Curiosa es la descripción que se hace en Campillo de Arenas en el registro de la defunción de un mendigo -por colitis y deshidratación-, haciendo referencia precisamente a la vestimenta: «Vestía chaqueta negra y pantalón muy viejo, camisa blanca sucia y en mal estado... $»^{29}$.

\section{Conclusión}

El primer franquismo fue un periodo caracterizado por el hambre, y la miseria, marcado no solo por las consecuencias inherentes a la Guerra Civil, sino por la política económica autárquica impuesta por el régimen franquista, que no hacía sino racionar la escasez y controlar y configurar una nueva sociedad: mientras unos tenían que preocuparse diariamente por su supervivencia, otros, afines al nuevo Estado, se enriquecían a través del gran estraperlo. Esta situación determinó unas condiciones de vida penosas para la mayoría de los españoles que tuvieron que malvivir en los años cuarenta. Tanto así que, la malnutrición,

27. Anselmo Marín García (Domingo Pérez, Granada, 25/07/1935). Entrevistado el 17 de junio de 2020.

28. Ibid.

29. Registro Civil de Campillo de Arenas (Jaén). Tomo 30. Defunción registrada en 1946. 
el hacinamiento de las viviendas, la insalubridad de las calles de zonas rurales y ciudades, la higiene pública y privada, los recursos desiguales recursos sanitarios -a pesar de los avances de la ciencia médica y la tendencia general española de reducción de la mortalidad-impactaron de manera notable en una población que sufrió una auténtica hambruna y las terribles consecuencias derivadas de ella. Unas psicológicas -las que se mantienen en la memoria y no se borran por mucho tiempo que pase- y otras físicas, que causaban la muerte o debilitaban el organismo humano y les hacían vulnerable ante las enfermedades.

Teniendo esto en cuenta, así como el marco teórico de las distintas transiciones: la demográfica, la epidemiológica y la nutricional, tomando como referencia tres poblaciones rurales de la Andalucía Oriental -Campotéjar, Dehesas Viejas y Campillo de Arenas- hemos analizado la tendencia de la mortalidad y las causas de muerte para el periodo que va desde 1939 a 1953, obteniendo información valiosa y de relevancia por su relación, inevitable, con la enfermedad y con el hambre.

Por un lado, hemos podido comprobar y refutar los periodos en los que el hambre y sus consecuencias tuvieron más importancia, a partir de la división entre las causas de muerte relacionadas directamente -enfermedades del tracto digestivo como la gastroenteritis y sus sucedáneas- e indirectamenteenfermedades del aparato respiratorio y las infecciosas- con el hambre. Así, establecemos tres periodos en los que las condiciones de vida de la población de la Andalucía Oriental tuvieron que ser muy complicadas. En un primer término, los años de la posguerra, desde 1939 a 1941, debido a las consecuencias de la contienda civil y el contexto internacional. En segundo lugar, entre 1946 y 1948, ocasionado por una coyuntura de malas cosechas, así como, en parte, por la ocultación de grano de los agricultores ante los cupos forzosos implementados por la intervención estatal de la economía. Y, por último, los años que van desde 1950 a 1952, entendidos como réplicas del periodo de crisis inmediatamente anterior, que van disminuyendo en intensidad, inducidas por las propias características de agricultura de secano y escasa productividad en la Andalucía Oriental, muy vulnerable ante cualquier cambio en las condiciones climáticas y ambientales. Esta relevancia del hambre, determinadas por la virulencia de las muertes relacionadas con este directamente, tiene además su conexión con las muertes originadas indirectamente por el hambre, puesto que podemos comprobar que estas aumentan en los años posteriores a las tres fases anteriormente comentadas, creando un vínculo entre los años más rigurosos de la escasez que no solo provocarían muertes, sino que debilitarían a la población para que, las enfermedades infecciosas, tiempo después, hicieran lo propio. 
Por otro, las condicionantes políticos -autarquía, abastecimiento, racionamiento y estraperlo-, socioeconómicos -zona rural de secano, plagas del campo, régimen de la propiedad, la idiosincrasia de vivir en el campo y no en la ciudad, la composición social, en su mayoría jornaleros sin tierra que dependen de su fuerza de trabajo, malas cosechas, condicionantes climáticos- junto con los higiénico-sanitarios -hacinamiento de las viviendas, sanidad e higiene públicas- y nutricionales- acceso al agua potable y al alimento- marcaron la tendencia de la mortalidad de la Andalucía Oriental en el periodo entre 1939 y 1953, donde las causas principales de muerte fueron ocasionadas por enfermedades del tracto digestivo y del aparato respiratorio (neumonías, bronquitis y bronconeumonías), así como debilidades congénitas (prematuridad, debilidad e insuficiencia general de desarrollo), junto con la tuberculosis o la fiebre tifoidea.

Existe, por lo tanto, una relación estrecha entre nutrición -además de otras variables- con las enfermedades y las causas de muerte. Así que, a pesar de la disminución de la tendencia de la mortalidad durante todo el siglo XX español, las desigualdades regionales, de abastecimiento alimentario y de distribución de recursos sanitarios, provocaron crisis de mortalidad, afectando de manera considerable a Andalucía y, singularmente, a la Andalucía Oriental, dejando patente que el hambre llegaba a matar. Aunque, a decir verdad, la importancia del hambre en la España de los años cuarenta no residía en su capacidad mortal, sino, precisamente, en su capacidad de no hacerlo.

\section{Bibliografía}

AGRA VARELA, José (1947). Mortalidad infantil, causas y remedios. SER. Revista Médico-Social, 63, 27-32.

AGUILAR CORDERO, María José (2002). Capítulo 6. Parte II. Recién nacido pretérmino. En Tratado de enfermería del niño y el adolescente. Cuidados pediátricos (73-82). Barcelona: ELSEVIER.

AGUILAR CORDERO, María José (2002). Gastroenteritis y diarrea en la infancia. En Tratado de enfermería del niño y el adolescente. Cuidados pediátricos (283-91). Barcelona: ELSEVIER.

AGUILAR CORDERO, María José; RODRÍGUEZ MORENO, María Ángeles (2002). Enfermedades infecciones en el niño y en el adolescente. Mononucleosis, tuberculosis, hepatitis y enfermedades de transmisión sexual. En Tratado de enfermería del niño y el adolescente. Cuidados pediatricos (438-47). Barcelona: ELSEVIER.

ARIAS VALLEJO, Eduardo (1941). Algunos conceptos fundamentales sobre alimentación. Semana médica española: revista técnica y profesional de ciencias médicas, 102, 209-2011. 
ARIAS VALLEJO, Eduardo (1941). Sobre un nuevo síndrome carencial. Semana médica española: revista técnica y profesional de ciencias médicas, 104, 270-73.

BARCIELA LÓPEZ, Carlos (1985). Las investigaciones sobre el mercado negro de productos agrarios. Situación actual y perspectivas. Revista de Historia Económica - Journal of Iberian and Latin American Economic History, 3, 3, 513-20 https://doi.org/10.1017/S0212610900014014.

BARCIELA LÓPEZ, Carlos; LÓPEZ ORTIZ, M. ${ }^{a}$ Inmaculada; MELGAREJO MORENO, Joaquín (1996). La intervención del Estado en la agricultura durante el siglo XX. Ayer, 21, 51-96.

BARRANQUERO TEXEIRA, Encarnación, PRIETO BORREGO, Lucía (2003). Así sobrevivimos al hambre: estrategias de supervivencia de las mujeres en la posguerra española. Málaga: Centro de Ediciones de la Diputación de Málaga.

BERNABÉU-MESTRE, Josep; CABALLERO PÉREZ, Pablo; GALIANA SÁNCHEZ, María Eugenia; NOLASCO BONMATÍ, Andreu (2006). Niveles de vida y salud en la España del primer franquismo: las desigualdades en la mortalidad infantil. Revista Demográfica Histórica, XXIV, 181-201.

BETETA AVIO, Ramón (2018). La mortalidad infantil, neonatal y postneonatal en la villa de Siles (Jaén), 1900-1969. Antropo, 39, 1-23.

CASTELLÓ BOTÍA, Isabel (2011). Transición alimentaria y evolución de la mortalidad asociada a causas nutricionales: la experiencia española (1900-1905). Alicante: Universidad de Alicante.

CAZORLA SÁNCHEZ, Antonio (2000). Las politicas de la victoria. La consolidación del Nuevo Estado franquista (1938-1953). Madrid: Marcial Pons Historia.

CERÓN TORREBLANCA, Cristian Macías (2005). Consolidación y evolución del franquismo en Málaga: 194-1959. Málaga: Universidad de Málaga.

CHRISTIANSEN, Thomas (2002). Intervención del Estado y mercado negro en el sector oleícola durante el primer franquismo. Historia Agraria: Revista de agricultura e historia rural, 27, 221-46.

CUBEL MONTESINOS, Antonio (1998). La continuidad del crecimiento económico en España, 1850-1936. Revista de Historia Económica, XVI, 3, 619-43 https://doi.org/10.1017/S0212610900007370.

CUSSÓ, Xavier; NICOLAU, Roser (2000). La mortalidad antes de entrar en la vida activa en España. Comparaciones regionales e internacionales, 18601960. Revista de Historia Económica XVIII, 3, 525-52. https://doi.org/10.1017/ S0212610900008727.

DEL ARCO BLANCO, Miguel Ángel (2006). «Morir de hambre». Autarquía, escasez y enfermedad en la España del primer franquismo. Pasado y Memoria: Revista de Historia Contemporánea. 5, 241-58 https://doi.org/10.14198/ PASADO2006.5.12.

DEL ARCO BLANCO, Miguel Ángel (2010). Hunger and the Consolidation of the Francoist Regime (1939-1951). European History Quarterly, 40, 3, 458-83 https://doi.org/10.1177/0265691410369744. 
DEL ARCO BLANCO, Miguel Ángel (2014). Producción de aceite, poder local y apoyos sociales del franquismo. Andalucía Oriental durante la Autarquía (1939-1951). Historia Agraria: Revista de agricultura e historia rural, 64, 71-101. DEL ARCO BLANCO, Miguel Ángel (2018). La corrupción en el franquismo. El fenómeno del «Gran Estraperlo». Hispania Nova: Revista de historia contemporánea 16, 620-45 https://doi.org/10.20318/hn.2018.4050.

DEL ARCO BLANCO, Miguel Ángel (2020a). Las hambrunas europeas del siglo XX y el lugar de «los años del hambre». En Miguel Ángel DEL ARCO BLANCO (Ed.). Los «años del hambre». Historia y memoria de la posguerra franquista. Madrid: Marcial Pons Historia, 23-51.

DEL ARCO BLANCO, Miguel Ángel (2020b). ¿Se acabó la miseria? La realidad socioeconómica en los años cincuenta. En Miguel Ángel DEL ARCO BLANCO; Claudio HERNÁNDEZ BURGOS (Eds.). Esta es la España de Franco. Los años cincuenta del franquismo (1951-1959). Zaragoza: Prensas de la Universidad de Zaragoza, 49-72.

DEL ARCO BLANCO, Miguel Ángel (2021). Famine in Spain during Franco's Dictatorship, 1939-52. Journal of Contemporary History, 56, 1, 3-27 https://doi. org/10.1177/0022009419876004.

DEL CURA GONZÁLEZ, María Isabel (2004). Problemas epidemiológicos, médicos y sociales del latirismo en España. Madrid: Universidad Autónoma de Madrid.

DEL CURA GONZÁLEZ, María Isabel; HUERTAS GARCÍA-ALEJO, Rafael (2007). Alimentación y enfermedad en tiempos de hambre. España, 1937-1947. Madrid: Consejo Superior de Investigaciones Científicas.

DOPICO, Fausto; LOSADA, Abel (2007). Cantidad y calidad de vida. El empleo de indicadores de mortalidad en la medición del bienestar. Revista Demográfica Histórica XXV, II, 167-192.

GÓMEZ REDONDO, Rosa María (1992). La mortalidad infantil española en el siglo $X X$. Madrid: Siglo Veintiuno de España Editores.

GONZÁLEZ DURO, Enrique (2003). El miedo en la posguerra. Franco y la España derrotada: la politica de exterminio. Madrid: Oberon.

HERNÁNDEZ BURGOS, Claudio (2016). De la cultura de guerra a la cultura de la victoria: los vencedores y la construcción de la dictadura franquista (1936-1951). Pasado y Memoria: Revista de Historia Contemporánea, 15, 123-48 https://doi.org/10.14198/PASADO2016.15.05.

HERNÁNDEZ BURGOS, Claudio; LERIA CASTIÑEIRA, Francisco J. (2020). Los rostros del hambre: autarquía, experiencias de miseria y estrategias de supervivencia durante la posguerra franquista (1939-1951). Historia Social, 97, 79-98. MARÍN GÓMEZ, Isabel (2004). El laurel y la retama en la memoria. Tiempo de posguerra en Murcia, 1939-1952. Murcia: Universidad de Murcia.

MARTÍNEZ CARRIÓN, José Miguel (2002). El nivel de vida en la España rural, siglos XVIII-XX. Nuevos enfoques, nuevos resultados. En José Miguel 
MARTÍNEZ CARRIÓN (Ed.). El nivel de vida en la España rural. Siglos XVIII - XX. Alicante: Universidad de Alicante.

MARTÍNEZ, Jesús (2003). Las raíces de Paloseco. Madrid: Edición Personal.

MCADAM, Alexander J.; SHARPE, Arlene H. (2010). Enfermedades infecciosas. En ROBBINS y COTRAN. Patología estrucutral y funcional, (331-98). Barcelona: ELSEVIER, 331-398.

MCKEOWN, Thomas (1978). El crecimiento moderno de la población. Barcelona: Bosch.

MIR CURCÓ, Concepción (2000). Vivir es sobrevivir: justicia, orden y marginación en la Cataluña rural de posguerra. Lleida: Milenio.

MOLERO MESA, Jorge (1994). Enfermedad y previsión social en España durante el primer franquismo (1936-1951). Dynamis: Acta hispanica ad medicinae scientiarumque historiam illustrandam, 14, 199-226.

MONTERO RODRÍGUEZ, A. (1943). Trastornos digestivos provocados por la patata. Hispalis Medica. Revista sevillana de medicina y cirugía, 57, 115-16.

MUÑOYERRO PRETEL, A.; BLANCO OTERO, M. (1943). Estudio 4o: Medios para solucionar el problema del abastecimiento infantil. Acta Pediátrica Española, 1, 7, 9-19.

NOTESTEIN, Frank (1953). Economic Problems of Population Change. Londres: Oxford University Press.

OMRAM, Abdel (1971). The epidemiology transition: A theory of the epidemilogy of population change. Milbank Mem Fund Quarterly, 49, 4, 509-38 https://doi. org/10.2307/3349375.

ORTEGA LÓPEZ, María Teresa (2007). Las miserias del fascismo rural. Las relaciones laborales en la agricultura española, 1936-1948. Historia agraria: Revista de agricultura e historia rural, 43, 543-49.

ORTEGA LÓPEZ, Teresa María; COBO ROMERO, Francisco (2004). Hambre, sumisión y miseria. Aspectos sociales y económicos de la agricultura de la Andalucía oriental durante la primera etapa del régimen franquista, 1936-1953. En Carlos NAVAJAS ZUBELDIA (Coord.) Actas del IV Simposio de Historia Actual: Logroño, 17-19 de octubre de 2002, (585-618).

PALANCA, J.A. (1941). Hacia el fin de una epidemia. Semana médica española: revista técnica y profesional de ciencias médicas, 125, 431-40.

PAYNE, Stanley G. (1987). El régimen de Franco, 1936-1975. Madrid: Alianza Editorial.

PÉREZ MOREDA, Vicente; REHER, David-Sven; SANZ GIMENO, Alberto (2015). La conquista de la salud. Mortalidad y modernización en la España contemporánea. Madrid: Marcial Pons Historia https://doi.org/10.2307/j.ctt20fw6sf.

POPKIN, Barry M. (1993). Nutritional Patterns and Transitions. Population and Development Review 19, 1, 138-95 https://doi.org/10.2307/2938388. 
QUESADA GARRIDO, Alejandro (2006). De la lucha por la tierra a la sujeción a los subsidios agrarios. Análisis etnohistórico de la inversión de flujos económicos en una comarca de Andalucía oriental (S. XVI-XXI). Granada: Universidad de Granada.

QUESADA GARRIDO, Alejandro (2017). Historia de la industria almazarera en Iznalloz. El Grupo y la Cooperativa de Nuestra Señora de los Remedios (19472017). Torres Editores.

RICHARDS, Michael (1999). Un tiempo de silencio: la guerra civil y la cultura de la represión en la España de Franco, 1936-1945. Barcelona: Crítica.

RODRÍGUEZ BARREIRA, Óscar J. (2008). Cambalaches: hambre, moralidad popular y mercados negros de guerra y postguerra. Historia Social, 77, 149-74.

RODRÍGUEZ BARREIRA, Óscar J. (2013). Migas con miedo. Prácticas de resistencia al primer franquismo: Almería, 1939-1953. Almería: Universidad de Almería.

RODRÍGUEZ OCAÑA, Esteban (2017). Tifus y laboratorio en la España de posguerra. Dynamis: Acta hispanica ad medicinae scientiarumque historiam illustrandam, 37, 2, 489-515.

ROMÁN RUIZ, Gloria (2015). Delinquir o morir. El pequeño estraperlo en la Granada de posguerra. Granada: Comares.

SANTIAGO DÍAZ, Gregorio (2017). Historia Local de Campotéjar. Granada: Editorial Comares.

SANTIAGO DÍAZ, Gregorio (2020). Cuando el hambre no solo mata: trastornos y enfermedades alimenticias en la España de los años cuarenta. En Miguel Ángel DEL ARCO BLANCO (Ed.) Los «años del hambre». Historia y memoria de la posguerra franquista. Madrid: Marcial Pons Historia, 273-291.

SANZ GIMENO, Alberto (2001). Infancia, mortalidad y causas de muerte en España en el primer tercio del siglo XX (1906-1932). Reis: Revista española de investigaciones sociológicas 95, 129-54. https://doi.org/10.2307/40184353.

SANZ GIMENO, Alberto; RAMIRO FARIÑAS, Diego (2002a). La caída de la mortalidad en la infancia en la España interior, 1860-1960.» Cuadernos de Historia Contemporánea, 24, 151-88.

SANZ GIMENO, Alberto; RAMIRO FARIÑAS, Diego (2002b). Infancia, mortalidad y niveles de vida en la España interior. Siglos XIX y XX. En El nivel de vida en la España rural. Siglos XVIII - XX., (359-403). Alicante: Universidad de Alicante. TURNER, Jerrold R. (2010). Tubo digestivo. En ROBBINS y COTRAN. Patología estrucutral y funcional (763-831). Barcelona: ELSEVIER https://doi.org/10.1016/ B978-1-4377-0792-2.50022-5.

VICIANA LÓPEZ, Francisco José (1998). La transición demográfica y sanitaria en Andalucía durante el siglo XX. Sevilla: Universidad de Sevilla. 